Gazi Mühendislik Bilimleri Dergisi

2019, 5(3): 216-226

Araștırma Makalesi/Research Article

https://dergipark.org.tr/gmbd

\title{
Rulman Seçimi İçin Bir Uzman Sistem
}

\author{
Yunus KAYIR ${ }^{\mathrm{a}}$, Ramazan MERGEN ${ }^{\mathrm{a}}$, Ömer ASAL $^{\mathrm{a}}$ \\ a Gazi Üniversitesi, Teknoloji Fakültesi, İmalat Mühendisliği Bölümü, 06500, Teknikokullar, ANKARA,TÜRKIYE
}

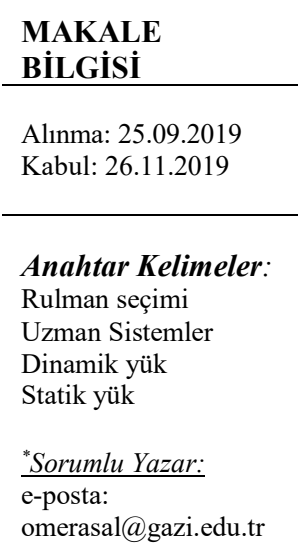

\begin{abstract}
ÖZET
Yapay Zeka tekniklerinden biri olan Uzman sistemler, günümüzde yaygın olarak kullanılmaktadır. Uzman sistemler, birden fazla seçeneğin içinden bilgi ve tecrübeyi kullanarak en uygun olanının belirlenmesini sağlayan bir yöntemdir. Rulmanlar, makinelerin dönen parçalarında yaygın olarak kullanılan standart makine elemanlarıdır. Piyasada, çok farklı teknik özelliklere sahip rulmanlar bulunmaktadır. Dolayısı ile kullanılacak olan bir yere göre uygun bir rulmanın seçimi uzmanlık gerektirmektedir. Bu çalışmada, rulman seçimi yapan bir uzman sistem geliştirilmiştir. Sistemde, rulmanlara yönelik birçok kural oluşturulmuştur. Kuralar, en uygun uygun rulman tipinin belirlenmesinde yönelik tasarlanmıştır. Kurallar, rulmanların yapısal özellikleri ve karșı koyacakları yük tipleri dikkate alınarak hazırlanmıştır. Belirlenen rulman tipi için sistem kullanıcıya, standart rulman kodunu vermektedir. Bununla birlikte, geliştirilen sistem, rulman iç çap (d), rulman dış çap (D) ve rulman genişliği (B) değerleri girilmesi durumunda kullanıcıya bir rulman kodunu da verebilecek yetenektedir. Rulman seçimi yapan sistemin geliştirilmesinde KAPPA-PC uzman sistem paket programı kullanılmıştır. Rulman bilgi tabanı için ORS rulman kataloğu bilgileri alınmıştır. Geliştirilen sistem ile ihtiyaç duyulan özelliklere yönelik olarak rulman tipinin belirlenmesi sağlanmıştır.
\end{abstract}

\section{An Expert System For Selection The Bearing}

\section{ARTICLE \\ INFO}

Received: 25.09 .2019

Accepted: 26.11 .2019

Keywords:

Bearing selection

Expert Systems

Dynamic load

Static load

\section{"Corresponding}

Authors

e-mail:

omerasal@gazi.edu.tr

\section{ABSTRACT}

Expert systems, one of the Artificial Intelligence techniques, are widely used today. Expert systems are a method to determine the most suitable one by using knowledge and experience from multiple options. Bearings are standard machine elements commonly used in rotating parts of machines. There are many different types of bearings on the market. Therefore, the selection of a suitable bearing that are used in a place requires expertise. In this study, an expert system, which selects bearings, was developed. Many rules were written for the system. The rules were designed to determine the most suitable bearing type. The rules are based on the structural characteristics of the bearings and the types of load they will resist. For the specified bearing type, the system gives the user the standard bearing code. However, the developed system is capable of providing a bearing code to the user in case the bearing inner diameter (d), bearing outer diameter (D) and bearing width (B) are entered. KAPPA-PC expert system shell program was used to develop the system, which makes selection of bearings. The ORS bearing catalogue was used for bearing knowledge base. The developed system provided to determine the bearing type for the required properties.

https://dx.doi.org/10.30855/gmbd.2019.03.02

\section{GİRIŞ (INTRODUCTION)}

Son y1llarda bilgisayar ve elektronik bilimlerinde yaşanan hızlı teknolojik gelişmeler, günlük yaşantımızı olduğu kadar işletmeleri de büyük ölçüde etkilemiştir. İşletmeler ve organizasyonlar, bu teknolojik gelişmelerin ortaya çıkardığı ürünleri kimya, eğitim-öğretim, tarım, sağlık ve endüstriyel 
gibi birçok alanda üretim, dağıtım, yönetim, tasarım, planlama, projelendirme, araç-gereç seçme, kontrol, bakım, teşhis, analiz gibi değişik amaçlar için kullanarak verimlilik artışı sağlamaya çalışmaktadırlar. Özellikle bilgisayar bilimlerinde, yazılım ve donanım alanındaki hızlı gelişmeler, insan gibi düşünen ve davranan sistemlerin ortaya çıkmasını sağlamıştır. 1950'li yıllardan beri bu alanda çalışmalar sürdürülmektedir. YZ: Yapay zeka (AI: Artfical Intelligence) olarak isimlendirilen bu alan, insanın düşünme yapısını anlamak ve bunun benzerini ortaya çıkaracak bilgisayar programlarını geliştirmeye çalışmak olarak tanımlanır [1]. İnsan faktöründen kaynaklanan olumsuzlukları en aza indirmek ve olabildiğince verimli çalışmayı sağlamak için yapılan araştırmalar neticesinde yapay zeka teknikleri geliştirilmiştir [2]. Yapılan istatistiksel çalışmalar sonucunda yapay zeka tekniklerinden biri olan uzman sistemlerin kullanılmasıyla, üretimin arttığı, kalitenin yükseldiği ve en önemlisi de maliyetin azaldığı görülmüştür [3]. Ayrıca uzman sistemlerin, birçok farklı alandaki zor seviyede sayılabilecek problemleri başarılı bir şekilde çözüme kavuşturması dikkat çekmelerindeki en önemli unsur oluşturmuştur [4].

Liu ve arkadaşları tarafından uzman sistem ve bulanık mantık kullanarak makaralı rulmanlardaki hatayı bulan "Rulman Uzmanı" adlı bir sistem geliştirilmiştir. Menü ile kontrol edilen ve bilgisayar bazlı olan bu sistemin oldukça kullanıcı dostu olduğu iddia edilmektedir [5]. Siang ve arkadaşları tarafindan yazılan makalede tasarımcının rulman seçimini yapmak için gerçekleştireceği tasarım faaliyetlerini taklit eden bir uzman sistemin geliştirilmesindeki aşamalar tanımlanmıștır [6]. Fegan, tarafından yazılan makalede; tasarımcıya yardımcı olma adına belirli bir çalışma koşulları dizisi için bir şaftı desteklemek üzere doğru bilyeli ve makaralı rulman kombinasyonlarını seçmede yardımcı olan uzman bir sistemin geliştirilmesinde kaydedilen aşamalar anlatılmıştır. Sistem ayrıca, rulman çiftinin montaj gereksinimleri konusunda tavsiyede bulunur [7]. Pathak ve arkadaşları tarafından yapılan çalışmada bilyeli ve makaralı rulmanların tasarımına yardımcı olmak için Bilgi Tabanlı Uzman Sistemin uygulanması tartışılmıştır. Bu makalede, bilyeli ve makaralı rulman tasarımında uzman sistem uygulamasını göstermek için kural tabanlı bir uzman sistem programından yararlanılmıştır [8]. Ramachandran ve arkadaşları yaptıkları araştırmada, mekanik sistemlerin tasarımı uzman sistem yaklaşımının uygulanmasına yönelik olmuştur [9]. Kaçal ve arkadaşları geniş bir ürün yelpazesi olan rulmanların bilgisayar destekli olarak seçilmesi üzerine çalışmışlardır. Veri tabanı olarak Türkiye'de üretim faaliyetlerini sürdüren ORS rulman firmasının rulman kataloglarını ve programlama dili olarak "Delphi 5" program dilini kullanılarak rulman seçimi için "RULSEÇ" isimli paket programı oluşturmuşlardır [10].

İncelenen çalışmalarda, geliştirilen uzman sistemleri için KAPPA-PC paket programının kullanıldığı görülmüştür [11]. Kayır ve Arkadaşları yaptıkları bir çalışmada, Yapılan bu çalışma ile delik delme operasyonlarında uzman olmayan bir kişinin takma uçlu matkapları ve kesme parametrelerini, kolay, hızlı ve doğru bir şekilde seçebilmesini sağlayan EIDT (Expert for Insert Drilling Tool) adlı bir uzman sistem geliştirmişlerdir [12]. Yine Kayır ve arkadaşları yaptıkları bir başka çalışmalarında, ExpertTS, Kappa-PC uzman sistem paket programı ile kesici ucun bir uzmana ihtiyaç olmadan kolayca seçilebilmesini sağlayan bir sistem geliştirmişlerdir. Böylelikle de vida açma işlemlerinde doğru ve hızlı karar verme sağlanmıştır [13]. Kaan ve Arkadaşları, yaptıkları bir çalışmada, imalatta kullnılan Aluminyum malzemelerinin seçimine yönelik Al_expert isimli bir uzman sistem geliştirmişlerdir [14]. Geliştirilen Al_expert sistem, istenen malzeme özelliklerini (mekanik özellikler, işlenebilirlik, vb.) dikkate alarak en uygun Aluminyum alaşımına karar verebilmektedir.

Yapılan çalışmalar değerlendirildiğinde geliştirilen uzman sistemlerin makine ve imalat sektörlerinde birçok uygulama için (makine elemanının, malzemelerin, işleme operasyonlarının, vb. unsurların seçimi) yaygın kullanıldığı görülmüştür.

Makine imalat sektörlerinde rulman seçimi hayati bir öneme sahiptir. Doğru karar vermek uzmanlık ve tecrübe gerektiren, zaman alıcı bir uygulamadır.

Dolayısıyla bu çalışmada, makine imalatında uygun rulmanın seçimini yapan bir uzman sistem geliştirilmiştir. Uzman sistemin geliştirilmesinde, KAPPA-PC programı tercih edilmiştir.

\section{YAPAY ZEKA (ARTIFICIAL INTELLIGENCE)}

Yapay zeka, insanın zeka gerektiren davranışlarının özelliklerini taklit eden bilgisayar sistemlerini tasarlamak ve geliştirmekle uğraşan bilgisayar biliminin bir branşıdır [13-15].

Yapay Zeka; makine görme yeteneği, konuşmayı tanıma, robotik, ses tanıma, tabi dil işleme, desen 
tanıma, makinenin öğrenmesi ve uzman sistemler gibi konularla ilgilenir [16].

Yapay zeka tekniklerinden olan uzman sistemler birçok alanda yaygın kullanılan ve ticari yönde birçok uygulamanın geliştirildiği bir yöntem olmuştur.

\subsection{Uzman Sistemler (Expert Systems)}

Uzman sistemler bir bilgi tabanından, bir veri bankasından, bir sonuç çıkarım mekanizmasından ve desteklenmiş programlardan meydana gelir [12-14, 17]. "Uzman sistem özel bir takım problemlerin çözümünde, uzmanların bilgisini ve çıkartım sürecini taklit etmeyi amaçlayan danışman programlardır [1]. Uzman sistemler yapay zeka programlama tekniklerinden birisi olup, belirli bir alanda uzman kişiler (doktor, mühendis, ekonomist, vb.) tarafından tanımlanmış bilgilere ve analitik kurallara dayanarak sadece o alanla ilgili problemlere bir uzman kişinin getirdiği şekilde çözümler getirebilen ve kararlar verebilen bilgisayar programlarıdır [18]. Uzman sistemin (ES) arkasındaki temel fikir, uzmanlığın bir insandan bilgisayara aktarılmasıdır [19].

Uzman sistemlerin geliştirilmesinde birçok bilgisayar programlama dili (c++, c\#, basic, pascal, vb.) kullanılmaktadır. Bununla birlikte, hazır geliştirilmiş ve amaca yönelik uyarlanabilen paket program (expert shell) seklinde olan uzman sistemlerde bulunmaktadir (Kappa-PC, Leonardo, Exys, vb). Uzman sistemler, kural tabanlı, bilgi tabanlı sistemler olarak da adlandirılırlar. Genelde uzman sistemler şu bileşenlerden meydana gelmektedir [20]:

- $\quad$ Bilgi Tabanı (Knowledge Base)

- Muhakeme Ünitesi (Inference Engine)

- Kullanıcı Arabirimi (User Intereface)

Uzman sistemler, bir sonuca ulaşılmasında kuralları kullanmaktadir. Kuralların değerlendirilmesinde, muhakeme edilmesinde iki temel teknik kullanılmaktadır.

- $\quad$ İleriye Doğru Zincirleme

- Geriye Doğru Zincirleme

İleriye doğru zincirleme (Forward chaining) Muhakeme ünitesi, problemin en başından başlayarak (IF cümlesinden) sonuç kısmına (THEN) ulaşmasıdır. $\mathrm{Bu}$ yöntem Tümevarım mantığı ile çalışır. Bütün kuralların şartı sağlayıp sağlamadığı göz önünde tutularak sonuca ulaşılır. Eğer şartlar sağlıyor ise
"Then" kısmında yer alan yargı cümlesi doğrudur. Bu cümle şartlara göre elde edilen sonuçtur.

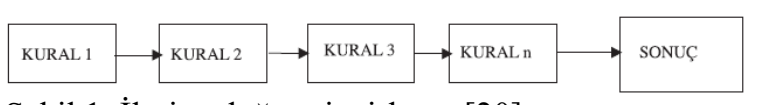

Şekil 1. İleriye doğru zincirleme [20](Forward chaining)

Geriye doğru zincirleme (Backward Chaning) Muhakeme ünitesi; problemi çözerken kuralın en sonu olan sonuç (THEN) cümlesi ile başlar ve şart (IF) cümleleri tatbik edilerek çözüm bulunur. Yani bu tür zincirleme Tümdengelim ilkesini temel olarak alır ve sonuç kısmını sağlayacak bütün kuralları tek tek inceler.

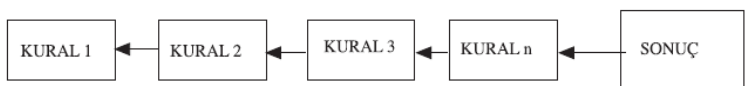

Şekil 2. Geriye doğru zincirleme [20] (Backward Chaning)

Geriye doğru zincirlemenin, Genişlik öncelikli ve Derinlik öncelikli olmak üzere iki şekli vardır. Genişlik öncelikli geriye doğru zincirleme, o anda eldeki amaca çözüm bulmak için tüm kuralların sonuç kısmını kontrol eder. Çözüm bulamazsa kuralların şart kısımlarına bakar. Derinlik öncelikli geriye doğru zincirleme ise, eldeki amaca çözüm bulmak için ilgili bir kural bulur ve bu kuralın önce şart kısmına bakar. $\mathrm{Bu}$ kuralın şart kısmı sonuca götürmezse başka bir kural arar [21].

\section{RULMANLAR VE RULMAN SEÇİİ (BEARINGS AND BEARING SELECTION)}

Rulman iç ve dış bilezikler arasında yuvarlanan elemanlar (bilye, makara, vb.) vasitası ile minimum sürtünmede çalışan, döner hareket yaparak ebadına ve biçimine göre farklı yükler taşıyan makine elemanlarıdır. Bu sayede malzeme kayarak değil yuvarlanarak hareket veya iş ürettiğinden sürtünme minimum olmakta ve enerji daha az kullanılmaktadır. Rulmanlar yatay ve dikey olarak çalışabildiği için radyal veya eksenel rulmanlar olarak tabir edilirler [22]. Genel olarak rulmanlar, dış bilezik, iç bilezik, yuvarlanma elemanları ve kafesten meydana gelir (Sekil 3). Kafes, yuvarlanma elemanlarını tek bir hat üzerinde tutar ve yüksek hızlara çıkıldığında, yuvarlanma elemanının birbirlerine ve her bir noktaya temas etmelerini önler [10]. 


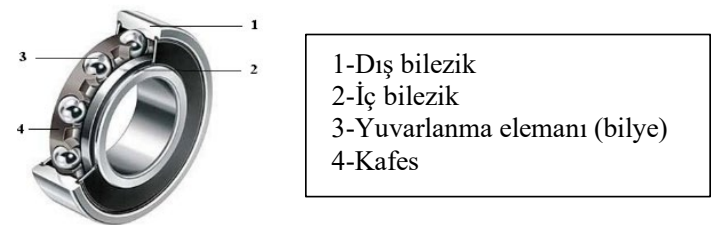

Şekil 3. Rulman Elemanları [10] (Bearing Companents)

\subsection{Rulmanların Sinıflandırılması (Bearing Classification)}

Rulmanların sinıflandirılması yuvarlanma elemanına göre yapılır.

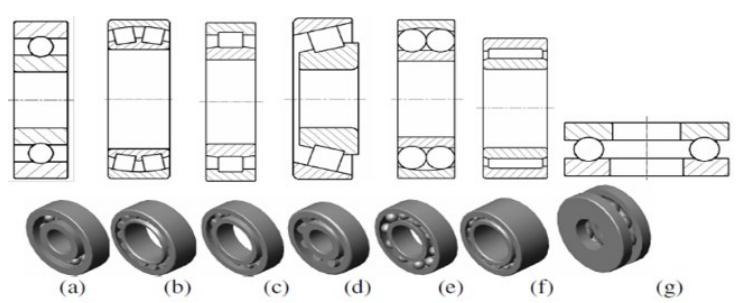

Şekil 4. Bazı rulman türlerinin 2B çizimleri ve 3B katı modelleri: a) Sabit bilyeli rulman, b) Oynak makaralı rulman, c) Silindirik makaralı rulman, d) Konik makaralı rulman, e) Oynak bilyeli rulman, f) İğneli rulman, g) Eksenel bilyeli rulman [24]

(2D drawings and 3D solid models of some bearing types:a) Deep groove ball bearing, b) Spherical roller bearing, c) Cylindrical roller bearing, d) Tapered roller bearing, e) Spherical ball bearing, f) Needle roller bearing, g) Axial ball bearing)

\subsection{Rulman Seçim Kriterleri (The Bearing Selection Criterias)}

Rulmanlar, hareketli millerin sabit gövdelere yataklanması için kullanılan makine elemanlarıdır. Makine teknolojisinin gelişmesiyle birlikte kullanım alanları ve oranları oldukça artmaktadır. Makine tasarımında vazgeçilmez olan bu makine elemanının çok fazla çeşidi bulunmaktadır. Bunlar en modern imalat yöntemleri ile ve yüksek kalitede malzeme kullanılarak üretilebilmektedirler. Birçok rulman arasından, çeşit ve ölçü bakımından en doğru rulmanı seçebilmek optimum makine tasarımı için oldukça önemlidir. Bütün rulmanlar, birbirinden farklı karakteristik özellik taşırken, birbirlerine benzeyen çok yönleri de vardır [23]. Bu yüzden en uygun olan rulmanı seçmek kolay olmamakla beraber rulman seçiminin asıl amacı, rulmanın uzun ömürlü çalışmasını ve görevini tam olarak yerine getirmesini sağlayabilmektir [22]. Rulmanların seçiminde, hacim ölçülerinin yanı sıra yatak yükünün cinsi ve miktarı, öngörülen çalışma ömrü ve yataklama emniyeti dikkate alınmaktadır [24]. Bir rulmandan beklenen en önemli özellikler uzun ömür, yüksek güvenirlik ve ekonomikliktir. Bunlara erişebilmek için tasarımcı, rulmanı etkiyen tüm şartları ve faktörleri düşünmek zorundadır. En ekonomik rulman şeklinin, yapılan seçim alternatifleri ile kıyaslanarak, rulmana etki eden faktörlerin ne ölçüde göz önüne alınması gerektiğine karar verilir [10]. Pek çok rulman arasından en doğru rulmanı seçebilmek için çeşitli dış etkenleri etraflıca düşünmek gerekir.

\section{GELISTTIRİLEN UZMAN SISTEM (DEVELOPED EXPERT SYSTEM)}

Geliştirilen Uzman Sistem Destekli Rulman Seçimi programı için KAPPA-PC programı kullanılmıştır. KAPPA-PC uzman sistem uygulamalarını gerçekleştirmek için hazırlanmış bir uzman sistem paket programıdır [25]. Bilgi tabanı, uzmanlık bilgisinin temsil edilmesi için kullanılan kurallar ve nesnelerden meydana gelir. Uzman sistem paket programları sayesinde uzman bir kişinin bilgileri bilgisayara aktarılıp diğerlerinin kullanımına sunulabilir ve uzman olmadığında bu sisteme danışılabilir. Uzman sistem paket programları klasik bilgisayar programlarından farklıdır. Klasik programlama dilleri ile uzun süre alacak bir uzman sistem geliştirme, bu tür paket programlar sayesinde daha kısa sürede hazırlanabilir. Klasik programlama dillerinde (Pascal, Fortran, $\mathrm{C}++$ vb.) geliştirilen programlar problemleri programcının düşündüğü tek tip yöntemle çözerler ve bu programlama dillerinin kendi kendilerine karar verme yöntemleri yoktur [26].

Geliştirilen Uzman Sistem Destekli Rulman Seçimi programında 12 çeşit rulman tipi ve bu rulman tiplerini belirlemek için 15 tane rulman seçim kriteri belirlenmiştir. "IF" - "THEN" yapıları kullanılarak 12 rulman tipi ve 15 rulman seçim kriteri için "TRUE" ya da "FALSE" şeklinde kurallar tanımlanmıştır. En ideal rulmanı seçebilmek için seçim kriterlerindeki özellikleri "çok iyi” ya da "iyi” olacak şekilde taşıyan rulmanlar karşısına "TRUE”, bu özellikleri hiç taşımıyorsa ya da az taşıyorsa "FALSE" şeklinde kurallar konulmuştur. Böylece ihtiyacımıza en iyi cevap verecek rulman tipi seçilmiş olacaktır. Şekil 7' de Sabit Bilyalı Rulmanların seçimi için tanımlanmış kurallar gösterilmiştir.

Rulman seçim kriterlerine göre rulman tipi belirlendikten sonra, ikinci aşamada ise rulmanın maruz kalacağı statik ve dinamik yükleri emniyetli bir şekilde taşıyabilecek ölçülerdeki rulmanlar tespit edilecektir. 


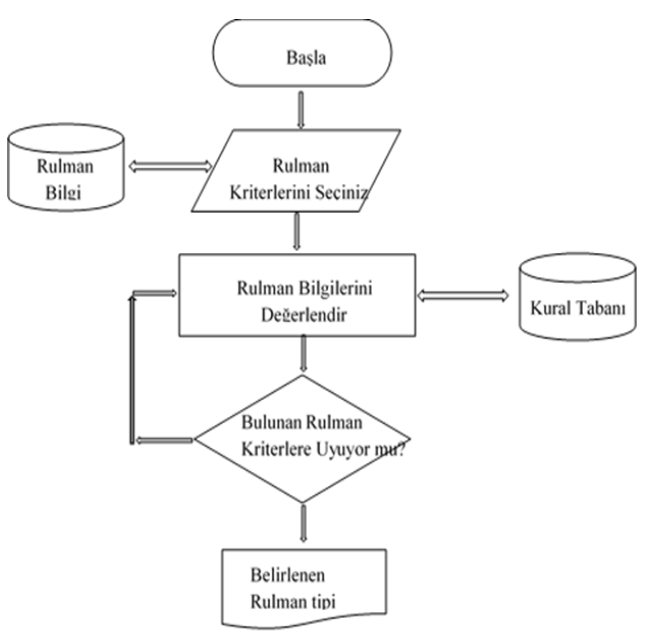

Şekil 6. Programın akış şeması (The Program flow chart)

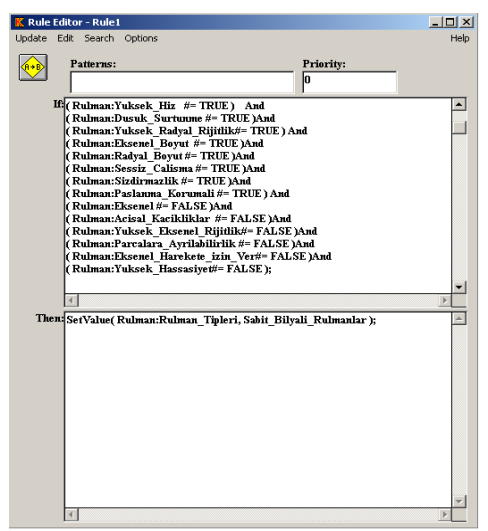

Şekil 7. Sabit Bilyalı Rulmanların seçimi için tanımlanan kurallar (Rules for selection of deep groove ball bearings)

Uzman Sistem Destekli Rulman Seçimi için geliştirilen programda Ortadoğu Rulman Sanayi (ORS) kataloğunda belirtilen geometrik ölçü değerleri ile statik ve dinamik yük değerleri esas alınmıştır. Kullanıcı tarafından girilen statik ve dinamik yüklerin ikisini birden aynı anda taşıyabilecek rulmanları tespit etmek için kurallar tanımlanmıştır (Şekil 8). Program kullanıcının girdiği yük değerlerini maksimum değer olarak kabul edecektir. Örnek olarak, statik yük değeri $0.22 \mathrm{kN}$ 'dan büyük, $0.51 \mathrm{kN}$ 'a eşit girildiğinde ve dinamik yük değeri ise $0.51 \mathrm{kN}$ 'dan büyük ve 1.06 kN'a küçük girildiğinde, geliştirilen sistem, ORS rulman kataloğuna göre Sabit Bilyalı Rulmanlar grubunda bulunan 624 rulman kodu, kullanıcıya önerecektir.

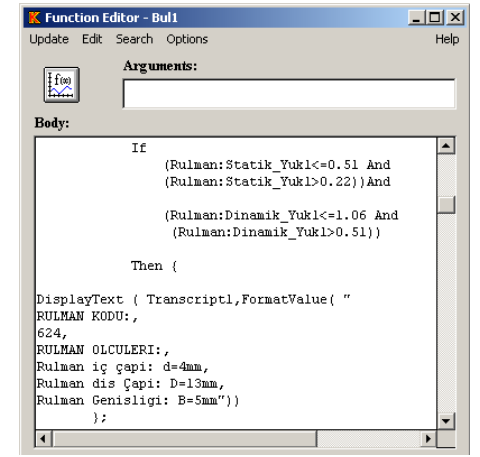

Şekil 8. Statik ve dinamik yüklere göre rulman kodu bulan örnek kural (Sample rule finding bearing code according to static and dynamic loads)

Uzman Sistem Destekli Rulman Seçimi, programı kullanıcının girdiği statik ve dinamik yüklere göre rulman kodunu bulmanın yanı sıra, her biri için ayrı ayrı olmak üzere rulman iç çapı $(\mathrm{d})$, rulman dış çapı (D) ve rulman genişliği (B) değerlerine göre de sorgulama yapıp en uygun rulman kodunu bulmaktadır. Bulunan rulman koduna göre bu rulmana ait rulman iç çap (d), rulman dış çap (D), rulman genişliği (B) ile ORS rulman kataloğunda belirtilen max taşıyabileceği statik ve dinamik yükleri de SONUÇ ekranında kullanıcıya sunmaktadır. Rulman iç çap değerine göre rulman kodu sorgulama kurallar Şekil 9'da gösterilmiştir. Kullanıcının girdiği iç çap değerinde ya da diğer sorgulama değerlerinde birden fazla rulman kodu varsa Uzman Sistem Destekli Rulman Seçimi programı bu kodu ve bu koda ait rulman değerlerini de yine SONUÇ ekranında kullanıcıya sunmaktadır.

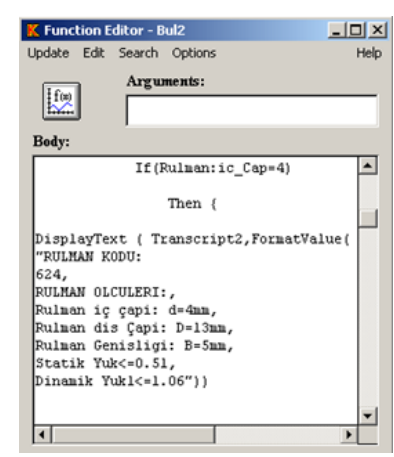

Şekil 9. Rulman iç çapına göre rulman kodu bulan örnek kural (Sample rule finding bearing code according to bearing inner diameter) 


\subsection{Program Menüleri ve Örnek Bir Uygulama (Program Menus and Sample Application)}

Programın kullanıcı ara yüzü, renkli, kullanımı kolay şekilde hazırlanmıştır (Şekil 10). Ara yüzün tasarımında görsel nesneler kullanılmıștır. Görsel nesneler (düğme, kutu, vb.), program üzerinde anlaşılır şekilde konumlandırılmıştır. Rulman seçiminin her adımı için görsel nesneler kullanılmıștır. Kullanıcının herhangi bir katalog ya da tablo kullanmasına gerek kalmamıştır. Gerekli yerlerde açıklama yazısı konularak kullanıcının programı kullanması kolaylaştırılmıştır.

Uzman Sistem Destekli Rulman Seçim Programının ana sayfasında rulman seçiminde dikkate alınan 15 yapısal kritere (Radyal yük taşıma, Eksenel yük taşıma, Açısal kaçıklık, Yüksek hız, Düşük sürtünme, Yüksek radyal rijitlik, Yüksek eksenel rijitlik, vb) yer verilmiştir. Tüm Kriterler için Kullanıcıya program sayfası üzerinden seçimi yapabilme imkanı verilmiştir (Şekil 10).

Kullanıcı bu 15 rulman seçim kriterinden herhangi biri hakkında bilgi almak istediği zaman, ilgili kriteri seçtikten sonra AÇIKLAMA butonuna tıklamalıdır. Örneğin, kullanıcı Radyal Yük Taşıma seçeneğini seçip AÇIKLAMA butonuna tıkladığında (Şekil 11 (a)), veva Eksenel Yük Taşıma seçeneğini seçip AC̣IKLAMA butonuna tıkladığında (Şekil 11 (b)) ekrana Radyal Yük veya Eksenel Yük ile ilgili görsel ve yazılı anlatımın olduğu pencere açılacaktır. Bu şekilde kullanıcı, diğer rulman seçim kriterleri hakkında da bilgi alabilecektir. Gerekli bilgi alındiktan sonra Tamam butonu ile bu pencere kapatılır.

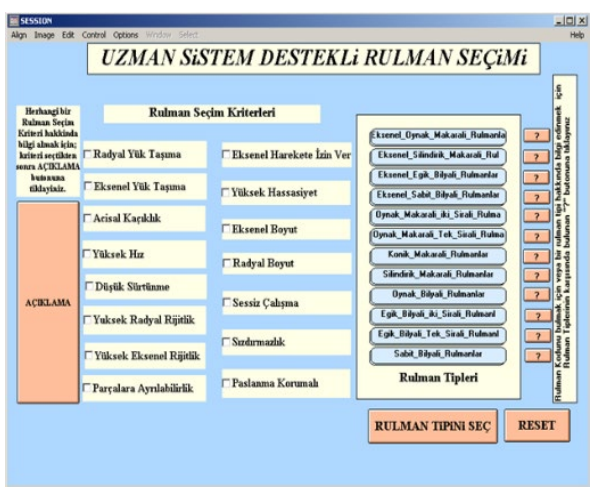

Şekil 10. Geliştirilen Uzman sistem rulman seçim programının ana sayfas1 (Mainpage of the expert systembearing selection program)

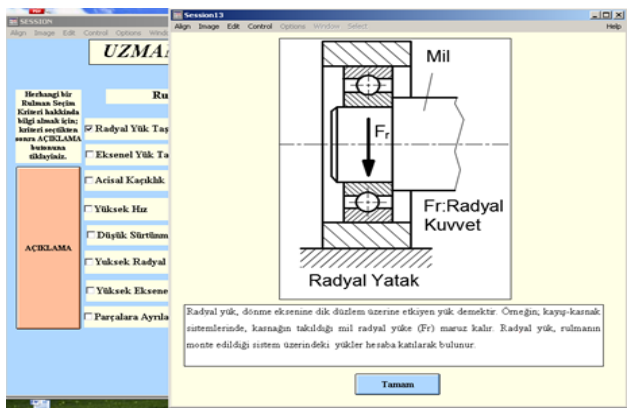

(a)

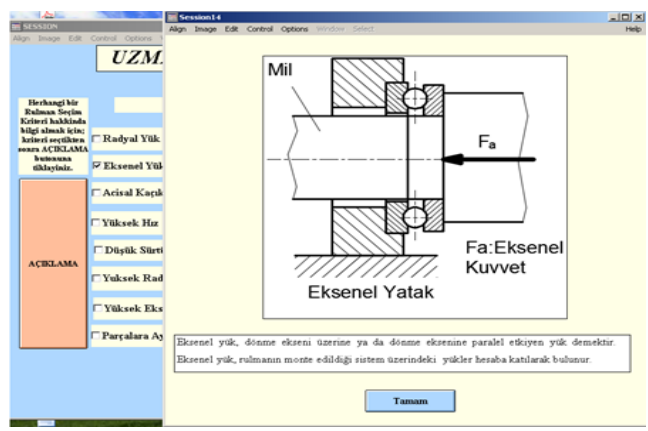

(b)

Sekil 11. (a) Radyal kuvvet (b) Eksenel kuvvet (Radial force and axial force)

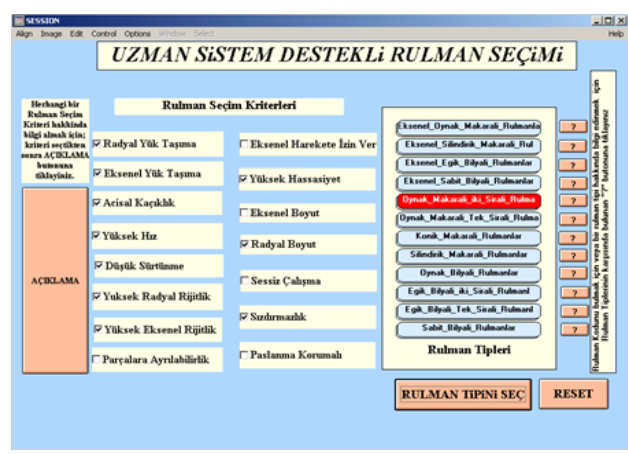

(a)

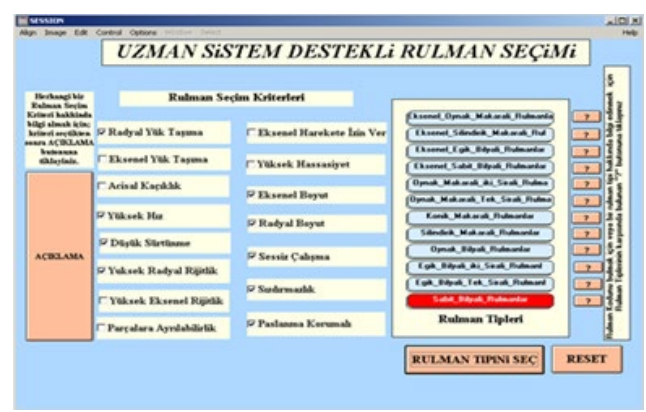

(b)

Şekil 12. Seçim kriterlere göre örnek rulman tipi seçimi (Sample bearing type selection according to selection criteria) 
En uygun rulman tipini bulabilmek için rulman seçim kriterleri işaretlenerek RULMAN TIPINI SEÇ butonuna tıklanır. Uzman Sistem Destekli Rulman Seçim Programımız, işaretlediğimiz rulman seçim kriterlerini çok iyi ya da iyi oranda taşıyan rulman tipinin üzerini kırmızı renkte yakarak, 12 rulman tipi arasından istediğimiz özelliklere en uygun rulman tipini bize gösterecektir (Şekil 12). Örneğin kullanıcı, rulman seçim kriterlerinden radyal yük taşıma, eksenel yük taşıma, açısal kaçıklık, yüksek hız, düşük sürtünme, yüksek radyal rijitlik, yüksek eksenel rijitlik, yüksek hassasiyet, radyal boyut ve sızdırmazlık özelliklerini seçip RULMAN TiPiNi SEC butonuna tıkladığında program bize Oynak Makaralı İki Sıralı Rulmanlar' 1 seçecektir (Şekil 12 (a)). Yine kullanıcı, rulman seçim kriterlerinden radyal yük taşıma, yüksek hız, düşük sürtünme, yüksek radyal rijitlik, eksenel boyut, radyal boyut, sessiz çalışma, sızdırmazlık ve paslanma korumalı özelliklerini seçip RULMAN TIPINi SEC Bilyalı Rulmanlar' 1 seçecektir (SSekil 12 (b)). Rulman tipi belirlendikten sonra rulman kodunu bulmak için ve ya bir rulman tipi hakkında bilgi edinmek için rulman tiplerinin karşısında bulunan ? butonuna tıklanmalıdır. Örnek olarak Şekil 12 (b)'de seçilen rulman seçim kriterleri sonucu programımızın gösterdiği Sabit Bilyalı Rulmanların karşısında bulunan $?$ tıklandığında Şekil 13 (a)'da gösterilen pencere ekrana gelecektir.

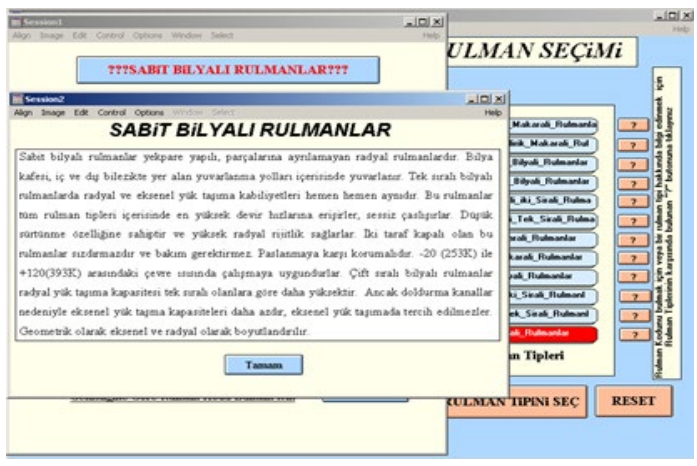

Şekil 13. Sabit bilyeli rulmanlar hakkında açıklama (Description of deep groove ball bearings)

$$
\text { Kullanic1 }
$$

$$
\text { ???SABIT BILYALI RULMANLAR??? }
$$

butonuna tıklayarak seçilmiş olan rulman tipi hakkında bilgi sahibi olacaktır (Şekil 13 b).

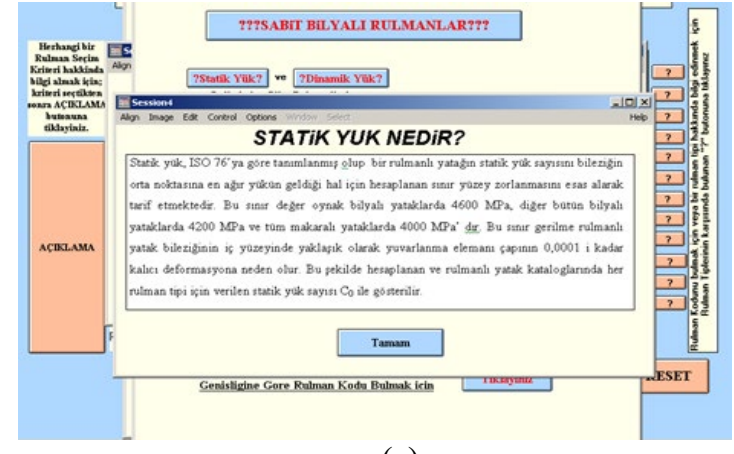

(a)

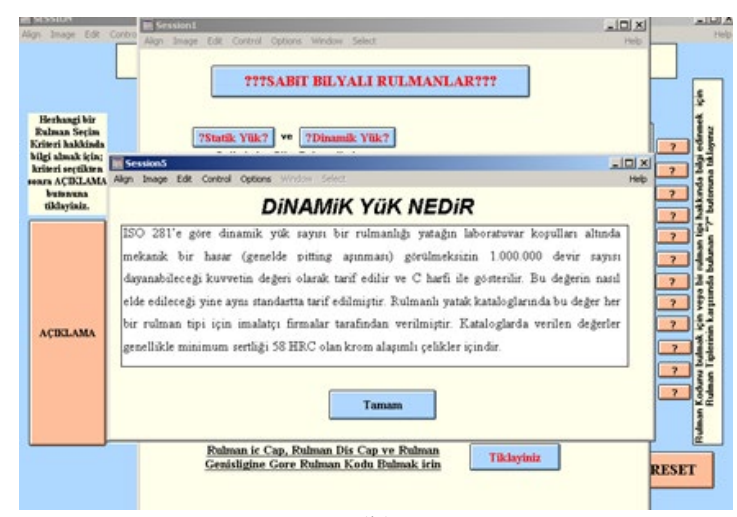

(b)

Şekil 13. Statik yük ya da dinamik yük hakkında açıklama (Description of static load or dynamic load)

Kullanıc1 yine bu sayfada bulunan ?Statik Yük? butonuna ya da ?Dinamik Yük? butonuna tıklayarak da Şekil 13 (a)'da gösterildiği gibi statik yük ya da Şekil 13 (b)'de gösterildiği gibi dinamik yük hakkında bilgi sahibi olacaktır.

Tablo 1'de ORS rulman sanayi kataloğunda verilen sabit bilyeli rulman boyutları ve taşıyabilecekleri statik ve dinamik yük değerlerinden bir bölümü verilmiştir. Burada verilen değerler max değerler olup programdaki kurallar bu değerlere göre tanımlanmıştır. Kullanıcının girdiği hem statik yük hem de dinamik yük değerinin ikisini birden sağlayan rulmanın kodunu hazırladığımız program SONUÇ ekranında gösterecektir. 


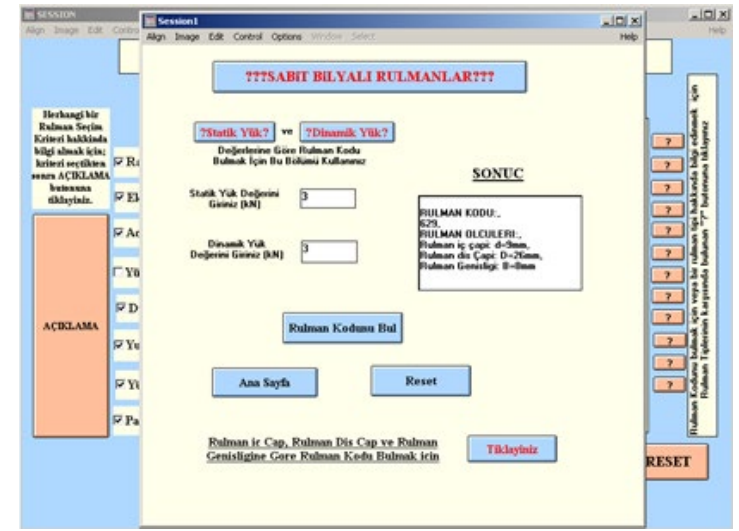

Şekil 14. Statik ve dinamik yükler sonucu rulman kodunun bulunmas1 (Determination of bearing code as a result of static and dynamic loads)
Örnek olarak kullanıcı hem statik yük değerini hem de dinamik yük değerini 3 olarak girmiş olsun. Rulman Kodunu Bul butonuna tıklandığında programımız, sonuç ekranında Rulman kodunu 629 olarak gösterecektir. Ayrıca programımız kullanıcıya, bulunan bu rulman koduna ait rulmanın iç çap (d), dış çap (D) ve rulman genişliği (B) hakkında da bilgi verecektir. Buradan istenirse Reset butonuna tıklayarak yeniden statik dinamik yük değerleri girilerek yeni sorgulama yapılabilir. İstenirse Ana Sayfa butonuna tıklayarak Ana sayfaya dönülür. Ana sayfadaki RESET butonuna tıklanarak program yeni bir rulman tipi sorgusuna hazır hale gelir. Rulman Seçim Kriterleri işaretlenerek yeni bir rulman tipi seçilebilir.

Tablo 1. Sabit bilyeli rulman boyutları için katalog değerleri (Catalog values for deep groove ball bearing dimensions)

\begin{tabular}{|c|c|c|c|c|c|}
\hline \multicolumn{3}{|c|}{ Ana ölçüler } & \multirow[t]{2}{*}{ Semboller } & \multicolumn{2}{|c|}{ Yük taşıma kapasitesi } \\
\hline d & D & B & & $\mathrm{C}_{\text {Iso }}$ & $\mathrm{C}_{01 \mathrm{so}}$ \\
\hline & $\mathrm{mm}$ & & & $\mathrm{kN}$ & $\mathrm{kN}$ \\
\hline 3 & 10 & 4 & 623 & 0.51 & 0.22 \\
\hline \multirow[t]{2}{*}{4} & 13 & 5 & 624 & 1.06 & 0.51 \\
\hline & 16 & 5 & 634 & 1.50 & 0.75 \\
\hline \multirow[t]{2}{*}{5} & 16 & 5 & 625 & 1.50 & 0.75 \\
\hline & 19 & 6 & 635 & 2.21 & 1.16 \\
\hline 6 & 19 & 6 & 626 & 1.91 & 1.00 \\
\hline \multirow[t]{2}{*}{7} & 19 & 6 & 607 & 1.91 & 1.00 \\
\hline & 22 & 7 & 627 & 2.60 & 1.37 \\
\hline 8 & 22 & 7 & 608 & 2.60 & 1.37 \\
\hline \multirow[t]{2}{*}{9} & 24 & 7 & 609 & 2.90 & 1.56 \\
\hline & 26 & 8 & 629 & 3.60 & 2.00 \\
\hline \multirow[t]{2}{*}{10} & 28 & 8 & 16100 & 4.00 & 2.24 \\
\hline & 26 & 8 & 6000 & 3.96 & 2.23 \\
\hline
\end{tabular}
genişliğine göre rulman kodu bulmak isteniyorsa bu sayfada bulunan Tiklayiniz butonuna tıklanır. Açılan pencerede (Şekil 15) kullanıcı rulman iç çap, rulman diş çap ya da rulman genişliği değerlerinden sadece birisini kullanarak rulman kodunu bulabilir. Bulunan rulman koduna ait rulmanın iç çap, dış çap, rulman genişliği, taşıyabileceği max statik ve dinamik yükler SONUÇ ekranında gösterilmektedir. Örneğin, kullanıcı rulman iç çap değerini $7 \mathrm{~mm}$ olarak girsin. Rulman Kodunu Bul
boNUÇ ekranında 607 ve 627 kodlu rulmanları
gösterecektir. Aynı zamanda bu rulmanlara ait rulman
iç çapı, rulman diş çapı, rulman genişliği,
taşıyabileceği statik yük ve taşıyabileceği dinamik 


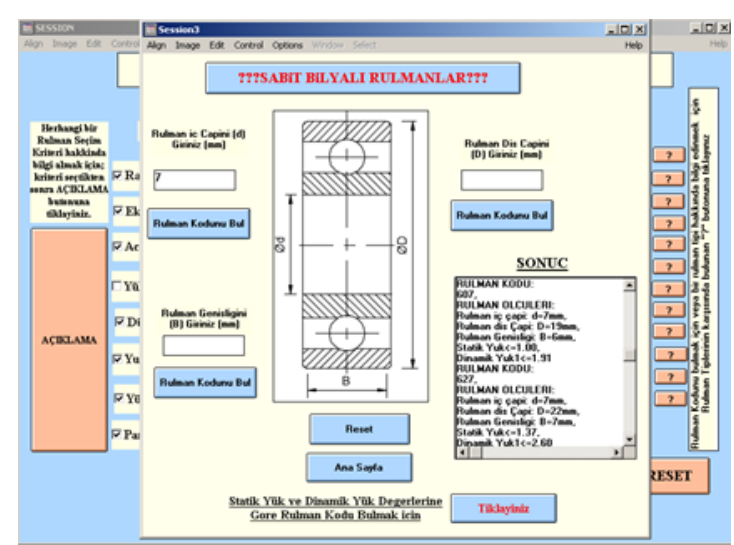

Şekil 15. Rulman iç çap değerine göre rulman kodunun gösteriliși (Indication of bearing code according to bearing inner diameter)

Eğer girilen rulman çap değerlerinde ya da rulman genişliğinde birden fazla rulman kodu varsa program bu rulman kodlarını da SONUÇ ekranında gösterecektir (Şekil 15). Ayrıca yine kullanıcıya bilgi vermesi açısından her rulman tipinin iki boyutlu resmi ve bu resim üzerinde rulman iç çapı $(\mathrm{d})$, rulman diş çap1 (D) ve rulman genişliği (B) gösterilmiştir. Böylelikle kullanıcı bu konularda da bilgi sahibi olacaktır.

Kullanıcı bu sayfada iken Reset butonu ile yeni bir sorgu için girilen değerleri sıfırlayabilir, Ana Sayfa butonu ile de ana sayfaya dönebilir. Ya da statik yük ve dinamik yükle rulman kodu bulma sayfasına da dönebilir.

\section{SONUÇ (CONCLUSION)}

Günümüzde hemen hemen her alanda kullanılan rulmanların seçimi oldukça karmaşık ve zaman alan bir işlemdir. $\mathrm{Bu}$ karmaşık işlemi kolaylaştırmak ve doğru rulman seçiminin yapılabilmesini için KAPPAPC paket programı ile bir uzman sistem geliştirilmiştir. Uzman Sistem Destekli Rulman Seçim Programı ile kullanım amaçlarına, kullanım yerlerine ve istenen özelliklere göre 15 tane rulman seçim kriterleri belirlenmiştir. Kullanıcının gerek duyması halinde, rulman seçim kriterleri hakkında görsel ve yazılı olarak kullanıcının bilgilenmesi sağlanmıştır. ORS rulman kataloğu kullanılarak bu kriterlere uygun 12 çeşit rulman tipi belirlenmiştir. Geliştirilen uzman sistem, girilen kriterlere göre en uygun rulmanı kullanıciya önermektedir. Bununla birlikte, kullanıcının gerek duyması halinde önerilen rulman tipi hakkında görsel ve yazılı olarak kullanıcının bilgilenmesi sağlanmıştır. Rulman tipi belirlendikten sonra kullanıcı isterse statik yük ve dinamik yük değerlerine göre, isterse de rulman iç çapı (d), rulman dış çapı (D) ya da rulman genişliği (B) değerine göre rulman kodunu bulabilmesi imkânı verilmiştir. Tasarlanan program kullanıcı yüzü sayesinde, rulman seçimi konusunda uzman olmayan kullanıcıların programı kolay kullanabilmesi ve en uygun rulmanı bulabilmesi sağlanmıştır. Böylelikle de Rulman seçimi ile ilgili olarak ihtiyaç duyulan uzman gereksinimi ve ilgili tablolara bakma ihtiyacı en aza indirgenmiştir.

\section{KAYNAKLAR (REFERENCES)}

[1] Dalmış, F., “CH Robofil 290 CNC Tel Erezyon Tezgahlarındaki Arızaların Tesbiti Amacıyla Bir Uzman Sistem Geliştirilmesi”, Trakya Üniversitesi, Fen Bilimleri Enstitüsü, Yüksek Lisans Tezi, 2006.

[2] Zeyveli, M., Güldas, A., "Taslama Operasyonları İçin Uzman Sistem Destekli Zımpara Taşı Seçimi”, Teknoloji Dergisi, Cilt 7, Sayı 2, s.241-249, 2004.

[3] Adal1, E., "Üretimde Uzman Sistem Çözümü”, Proceedings of the First Turkish Symposium on Intelligent Manufacturing Systems, 1996. 525-535, s.30-31.

[4] Dalmış, S., "Bilgisayar Destekli Üretim Sistemleri Ve Bir Ekici Çark Tasarımı”, Trakya Üniversitesi Fen Bilimleri Enstitüsü, Yüksek Lisans Tezi, 2000.

[5] Liu, T.I., Singonahalli J.H., Iyer N.R., "Detection of Roller Bearing Defects Using Expert System and Fuzzy Logic", Department of Mechanical Engineering, California State University-Sacramento, Sacramento, CA, U.S.A. 1995. doi.org/10.1006/mssp.1996.0041

[6] Sim, S. K., Chan Y.W., “A Knowledge-Based Expert System for Rolling Element Bearing Selection in Mechanical Engineering Design", School of Mechanical and Production Engineering, Nanyang Technological University, Nanyang Avenue, Singapore, 2263, 1991.

doi.org/10.1016/0954-1810(91)90035-M

[7] Fagan, M. J., "Expert systems applied to mechanical engineering design-experience with bearing selection and application program", Computer-Aided Design, Volume 19, Issue 7, 361367, 1987.

doi.org/10.1016/0010-4485(87)90036-4

[8] Pathak, M. A., Ahluwalia, “An Expert System for the Design and Selection of Ball Bearing Parameters", Industrial Engineering Department, West Virginia University, Morgantown, WV, 317-322, 1990. doi.org/10.1016/0261-3069(90)90015-C 
[9] Ramachandran, N., Shah, A., Langrana, N.A., "Expert System Approach in Design of Mechanical Components, Department of Mechanical and Aerospace Engineering", Rutgers, The State University of New Jersey, New Brunswick, New Jersey, 185-195, 1988. doi.org/10.1007/BF01213980

[10] Kaçal A., Işık A., Erginli M., "Bilgisayar Destekli Rulman Seçimi”, Fen Bilimleri Dergisi, Dumlupınar Üniversitesi, Kütahya, 2003.

[11] Tan, C., F., vd, "An Expert Machine Tools Selection System for Turning Operation", 7th International Conference on Cooling \& Heating Technologies (ICCHT 2014), Netherlands, 2014.

[12] Kayır, Y., Demirer, E, Güneş, S., “Takma Uçlu Matkap Ve Kesme Parametrelerinin Seçimi için Bir Uzman Sistem", El-Cezerî Fen ve Mühendislik Dergisi, 5, 2, 797-806, 2018.

DOI: $10.31202 /$ ecjse.424109

[13] Kayır, Y., Güneş, S., Demirer, E., "Vidaların Açılmasında Kesici Uç Seçimi Yapan Bir Uzman Sistem", Gazi Mühendislik Bilimleri Dergisi, 4, 3, 176-182, 2018.

DOI: 10.30855/GJES.2018.04.03.004

[14] Telek, K., Kayır, Y., "To Select Aluminum Alloys for Many Aplications With an Expert System", International Conference on Advanced Technology \& Sciences (ICAT'16), Konya, 2016.

[15] Dilipak, H., "Torna Operasyonlar İçin Uzman Sistemlerine Dayalı Kesici Seçimi”, Makina Imalat Kongresi, ITÜ, İstanbul, Haziran 1997.

[16] Gülesin, M., "Sanayide Uzman Sistem Uygulamaları", Ders Notları, Ankara, 1997.

[17] Sell, P. S., Expert Systems: A Practical Introduction, Macmillan Publishers Ltd, p 1-7, 1985.

[18] Jonhson, P.E., "What Kind of Expert Should A System Be?", The Journal of Medicine and Philosophy, Vol. 8, p77-79, 1983.

doi.org/10.1093/jmp/8.1.77

[19] Sahin, I., Calp, M., Özkan, A., “An Expert System Design and Application for Hydroponics Greenhouse Systems", Gazi University Journal of Science, 27(2), 809-822, 2014.
[20] Özkan, M.T., Gülesin, M., "Uzman sistem Yaklaşımı ile Civata ve Dişli Çark Seçimi”, Turk J Engin Environ Sci, 25, 169-177, 2001.

[21] Winstanley, G., Artifcial Intelligence in Engineering, New York, 1991.

[22] Akkurt, M., Makine Elemanlarl I, Birsen Yayınevi, İstanbul, 1990.

[23] Çiçek, A., "Dinamik ve Statik Yüklere Göre Bilgisayar Destekli Rulman Seçimi”, Afyon Kocatepe Üniversitesi, Fen ve Mühendislik Bilimleri Dergisi, 7, 2, 91-103, Afyon, 2007.

[24] ORS rulmanları kataloğu, Ankara.

[25] Ugraş, A., Kayır, Y., "An Expert System for Boring Tools Used for Machining Holes", International Conference on Advanced Technology \& Sciences (ICAT'16), Konya, 2016.

[26] Başak, H., "Uzman Sistem Yaklaşımı ile Vida Açma Operasyonları İçin Kılavuz Seçimi”, Pamukkale Üniversitesi, Mühendislik Bilimleri Dergisi, Cilt:5, Sayı 1, 901-910, Denizli,1999.

\section{Yunus KAYIR}

1970 Yalova doğumlu olan Yunus Kayır, 1992 yılında Gazi Üniversitesi, Teknik Eğitim Fakültesi Makine Eğitimi Bölümünden mezun oldu. 1993 Yılında mezun olduğu bölüme araştırma görevlisi oldu. Gazi Üniversitesi Fen Bilimleri Enstitüsünde, 1992 yılında Yüksek Lisans ve 2001 yılında ise Doktora çalışmalarında bulundu. Gazi Üniversitesi Teknik Eğitim Fakültesi, Makine Eğitimi Bölümü, Talaşlı Üretim Anabilim Dalında, 2002 Yılında Öğr. Grv, 2008 Yılında Dr. Öğr. Üyesi, olarak çalıştı. 2018 yılında Gazi Üniversitesi Teknoloji Fakültesi İmalat Mühendisliği Bölümüne Doç. Dr. olarak göreve başladı. Uzman Sistemler, İşlenebilirlik, kesme kuvvetleri, Optimizasyon konularında makaleleri bulunan Doç. Dr. Yunus Kayır, evli olup 3 çocuk sahibidir. 


\section{Ramazan MERGEN}

Afyonkarahisar doğdu. Gazi Üniversitesi Teknik Eğitim Fakültesi Makine Eğitimi Bölümü, Talaşlı Üretim Öğretmenliği Anabilim dalından 1997 yılında mezun oldu. Teknik öğretmen olarak yurdun birçok yerinde görev yaptı. 2004 yılında Yüksek lisansı bitiren Ramazan Mergen, Gazi Üniversitesi Teknoloji Fakültesi, İmalat Mühendisliği Bölümünde Doktora çalışmalarını sürdürmekte olup, Ankara/Yenimahalle Şehit Mehmet Şengül Mesleki ve Teknik Anadolu Lisesinde okulunda Makine Teknolojisi Öğretmeni olarak görev yapmaktadır.

\section{Ömer ASAL}

1974 yılında doğdu. Gazi Üniversitesi, Teknik Eğitim Fakültesi, Makine Eğitimi Bölümü, Talaşlı Üretim Öğretmenliği Anabilim dalından 1998 yılında mezun oldu. 1999-2000 yıllarında Bolu ve Ankara'da teknik öğretmenlik yaptı. 2000 yılında Gazi Üniversitesi, Teknik Eğitim Fakültesi, Makine Eğitimi Bölümü, Üretim Planlama ve Kontrol Eğitimi Anabilim dalından Arş. Gör., 2009 yılında Öğretim Görevlisi, 2011 yılında Yard. Doç. Dr. ünvanını aldı. 2001 yılında Yüksek lisansını, 2009 yılında doktorasını bitirdi. Üretim Yönetimi, İşletme Yönetimi, İşlenebilirlik, İş Sağlığı ve Güvenliği konularında çalışmaları vardır. Evli ve bir çocuk sahibidir. 